\title{
Effect of Earthquake Ground Motion Duration on the Seismic Response of a Low-Rise RC Building
}

\author{
Martin O. Martineau, Alvaro F. Lopez $\mathbb{D}$, and Juan C. Vielma \\ Escuela de Ingeniería Civil, Pontificia Universidad Católica de Valparaíso, Valparaíso 2362804, Chile \\ Correspondence should be addressed to Alvaro F. Lopez; alvaro.lopez@pucv.cl
}

Received 25 June 2020; Revised 14 September 2020; Accepted 18 September 2020; Published 5 October 2020

Academic Editor: Haiyun Shi

Copyright ( 2020 Martin O. Martineau et al. This is an open access article distributed under the Creative Commons Attribution License, which permits unrestricted use, distribution, and reproduction in any medium, provided the original work is properly cited.

\begin{abstract}
This paper investigates the effect of earthquake ground motion duration on the seismic response of a low-rise reinforced concrete shear wall building. Two sets of spectrally equivalent ground motion sets were determined to isolate the effect of duration from other earthquake record characteristics. A numerical model that accounts for P-delta effects and degradation of strength and stiffness of the structural elements was used. Detailed nonlinear dynamic analysis for both the design and collapse levels of shaking was performed, considering the spectral acceleration at the fundamental period of vibration with intensity measure and material strains as engineering demand parameters. The results showed that at the design level of shaking, slightly larger interstory drifts were obtained under the short-duration events. However, the maximum values for interstory drifts were small, and minor damage is expected in the structure. When both seismic record sets were incrementally scaled until collapse, a slight increase in the material strains was found under the short-duration seismic events. Overall, it is indicated that ground motion duration does not influence the seismic response of low-rise buildings with low deformation capacity.
\end{abstract}

\section{Introduction}

In recent years, there has been a resurgence interest in studying the effect of ground motion duration on the seismic performance and collapse assessment of structures. This topic's interest has been primarily due to the field observation after large-magnitude long-duration earthquakes such as the 2010 Maule, Chile $\left(M_{\mathrm{w}} 8.8\right)$, and the 2011 Tohoku, Japan $\left(M_{\mathrm{w}} 9.0\right)$, megathrust earthquakes, which caused significant structural damage to critical infrastructures like bridges and buildings [1-4]. Moreover, such events and others from subduction regions have made available new long-duration strong motion records allowing a better study of the effects of earthquake duration on structural performance. For instance, the lack of available long-duration ground motion records in the past required the generation of artificial records to address this topic adequately [5-7]. The previous events have shown that ground motion duration should be duly considered in structural design. However, the effect of ground motion duration is not yet explicitly considered as a parameter in current seismic design codes [8-10] and performance assessment throughout the world $[11,12]$.

A vast number of research studies on the effects of ground motion duration on structural performance have been reported in the literature in the past decades, often with inconclusive results due to the parameters used. On the one hand, investigations using cumulative response measures, such as the number of inelastic cycles or energy dissipation, showed a good correlation between duration and damage [13-16]. On the other hand, research studies using only peak response measures, such as peak deformation or peak interstory drift, did not show a significant influence of duration on structural response $[15,17,18]$. However, the inadequacy of structural models in capturing the effect of energy capacity degradation, cyclic and in-cycle strength degradation, and scarcity of long-duration ground motion records made it difficult to address duration effects in previous research adequately [19]. Likewise, the problem of isolating duration from other key explanatory variables of the ground motion, such as frequency content, spectral 
amplitude, and spectral shape, added another challenge since the spectral content of the earthquake record can be modified [20]. In this regard, using spectrally equivalent ground motion pairs for isolating the effect of duration has made available a more robust way of analyzing ground motions for nonlinear dynamic analyses since the spectral content is almost not altered [21, 22].

More recent investigations employing numerical models that captured structural components' degradation have shown that long-duration ground motions can induce higher deformations and affect the structural collapse capacity [22-25]. Chandramohan et al. [22] presented results showing that longduration records induce higher deformations for large shaking intensities. By analyzing 2D models of a modern 5-story steel special moment frame and a single reinforced concrete (RC) bridge pier, they concluded that the median collapse capacity of the structural systems could experience a reduction of $29 \%$ and $17 \%$, respectively, when the structures are subjected to longduration motions. Raghunandan and Liel [23] studied the influence of duration on the collapse capacity of eight nonductile RC frames and nine modern ductile RC frames, using 2D nonlinear models. The authors concluded that earthquake duration plays a significant role in the collapse resistance of the structural systems. They reported reductions in the collapse resistance ranging from $26 \%$ to $56 \%$ due to duration effects, impacting the buildings' vulnerability. Barbosa et al. [24] quantified the influence of duration on the damage (i.e., not only at collapse stage) of 3-, 9-, and 20-story steel buildings designed according to pre-Northridge codes. Spectrally equivalent records from subduction and crustal earthquakes were used as input in the $2 \mathrm{D}$ nonlinear models. It was concluded that the increase in energy dissipation demands in the structures subjected to long-duration motions significantly increased the expected levels of structural damage at the higher intensities of shaking. Belejo et al. [26] studied the seismic behavior of a substandard plan-asymmetric RC framed building through 3D nonlinear modeling and found that ground motion duration influence is evident only for intensities leading to the collapse of the structure. This result agrees with the conclusions reported by Raghunandan and Liel [23] since structural systems with low ductile capacity are not influenced by earthquake duration due to the inability to reach large deformations and dissipate energy before failure. Bravo-Haro and Elghazouli [25] analyzed 50 steel moment frames through detailed nonlinear dynamic analysis using a suite of 77 spectrally equivalent pairs of short and long earthquake records. Similar to previous studies, they reported that the effects of duration are significant for structures showing high rate of cyclic degradation levels. Reductions of about $20 \%$ on the collapse capacity were observed due to duration, reaching up to a $40 \%$ reduction in buildings with a high cyclic degradation rate. Samanta and Pandey [27] studied the effect of duration on a 15story RC building, and they found that earthquake duration can become a determining factor in the levels of maximum peak story drift ratio under low hazard levels. Bhanu et al. [19] found a reduction in ductile RC framed structures' dynamic deformation capacity under the increased cyclic demands imposed by long-duration ground motions. Vega and Montejo [28] found that long-duration records impose larger inelastic demands and that the effect of duration is more detrimental in relatively rigid structures and poorly detailed flexible structures. Liapopoulou et al. [29] investigated the effect of duration on a series of ductile SDOF models and reported up to $60 \%$ reduction in the collapse capacity due to duration effects in the case of flexible bilinear systems under low levels of $P-\Delta$ effect.

On the other hand, the structural response to long-duration events is directly related to ductility, a property necessary to study under earthquake-induced deformations on buildings. Nonetheless, traditional analysis methods do not consider the effects of earthquake duration and the use of deteriorating structural models that directly affect the structure's demand $[19,30]$. Therefore, the assessment of the effects of earthquake ground motion duration on these structures is not feasible. As a matter of fact, current seismic design practice for reinforced concrete structures in Chile is based on the conventional codeprescribed force method. However, after the recent occurrence of significant seismic events, such as the 2010 Maule earthquake, changes to the regulation were introduced afterwards to improve the structural response of walls by ensuring the ductility of these and including recommendations for estimating structural deformations. It is well known that Chile is located in one of the most seismically active regions of the world, where the geological conditions (from a tectonic point of view) near the Chilean coast mostly consist of interplate areas where subduction events occur frequently and are generally of large magnitude and also of long duration [31]. This last feature has not been considered in the seismic-resistant design despite the local conditions; therefore, it is necessary to promote research works that include duration effects on structural behavior.

In this paper, the effect of ground motion duration on the seismic performance of RC building structures is investigated. A sample four-story RC shear wall building is used as a case study. This building represents a typical low-rise residential building located in Central Chile designed according to current Chilean seismic provisions. A 3D nonlinear finite element model of the sample structure is developed in SeismoStruct [32], which allows incorporating the in-cycle and cyclic deterioration of stiffness and strength as well as the fiber modeling approach with material inelasticity for structural members. A set of 20 spectrally equivalent pairs of long and short earthquake records is used to evaluate the effects of ground motion duration on the structural response. Particular attention is given to effects of duration on material strains and interstory drift ratios. The results in this investigation indicate that ground motion duration does not play a key role in the damage state of the low-rise building.

\section{Sample Building and Model Description}

2.1. General Description. The sample structure corresponds to an existing low-rise RC shear wall building of which structural configuration is typical of residential housing built in Chile. The prototype building is a 4-story structure with a story height of $2.44 \mathrm{~m}$. The building's lateral load and gravityresisting systems comprise interior and outer $\mathrm{RC}$ shear walls in both longitudinal and transverse directions and $12 \mathrm{~cm} \mathrm{RC}$ slabs at each floor. The typical floor plan and elevations are illustrated in Figure 1. The compressive strength of concrete is 
(1)

(2)

(3)

(4)

(5)

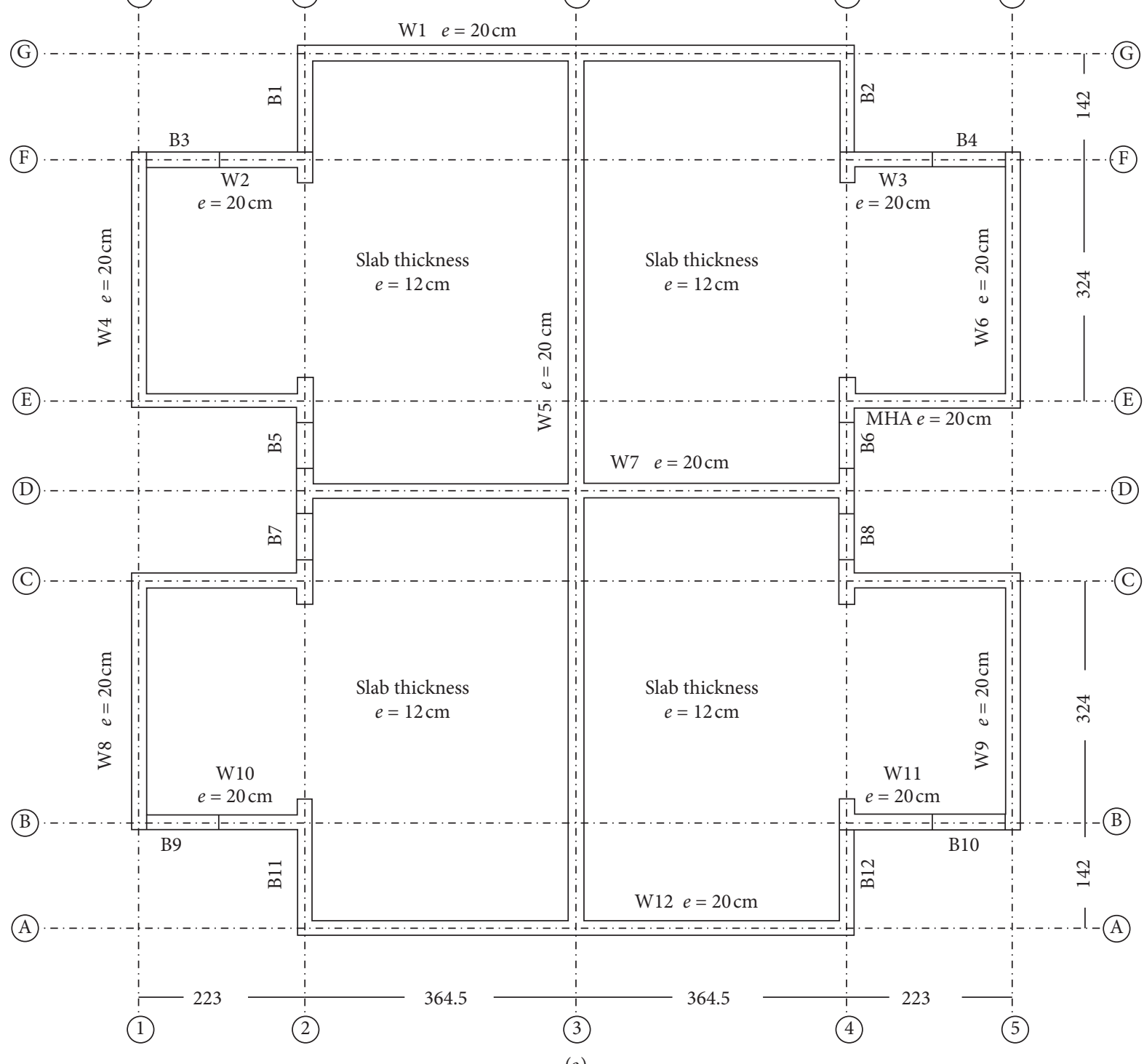

(a)

FIgURE 1: Continued. 


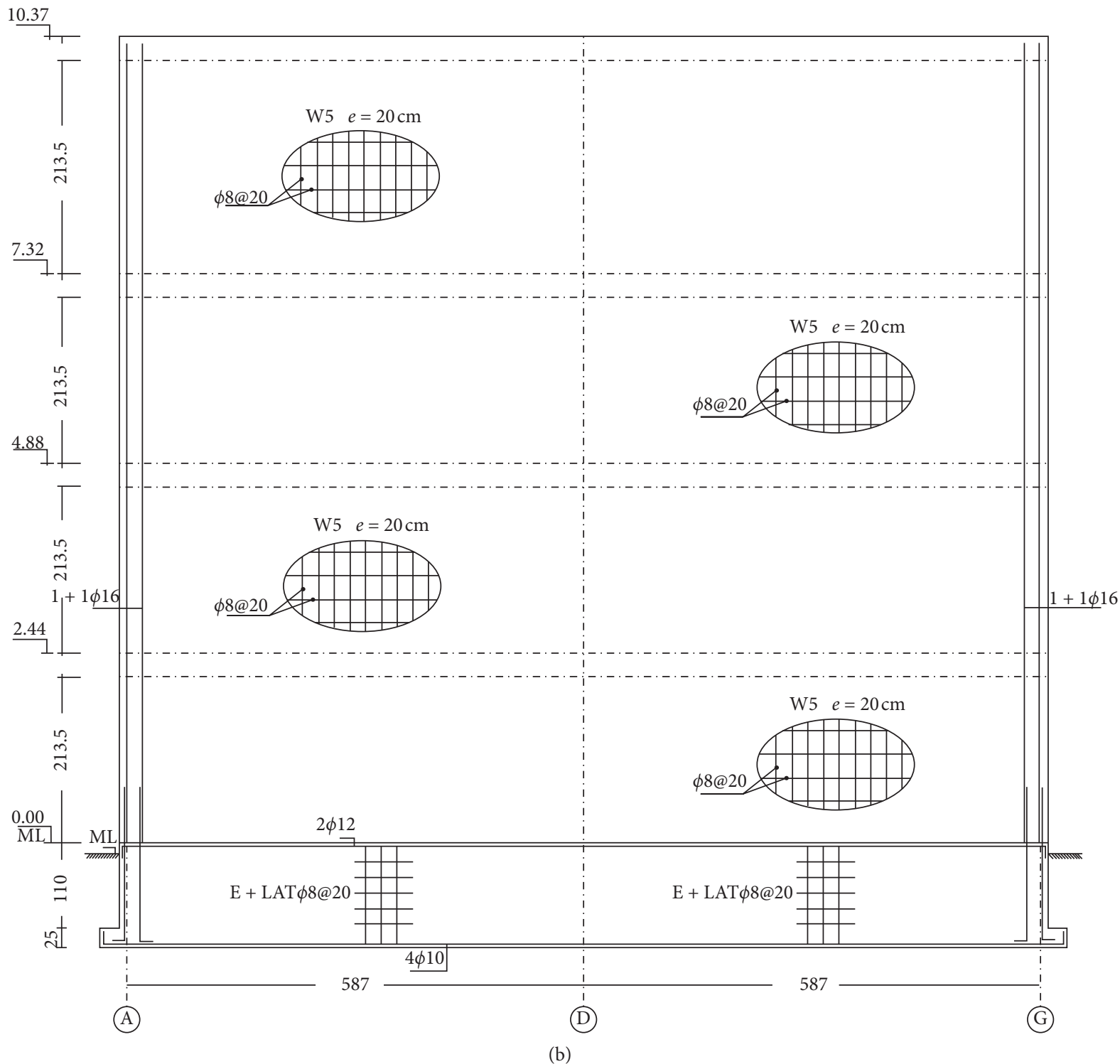

FIGURE 1: Sample residential housing: (a) typical floor plan of the building and (b) elevations of outer longitudinal and inner transverse shear walls.

assumed to be $20 \mathrm{MPa}$, and the tensile strength of reinforcement is $420 \mathrm{MPa}$. The floor area is about $120 \mathrm{~m}^{2}$ per story, and the dead and live loads were calculated approximately as $27.9 \mathrm{kN} / \mathrm{m}^{2}$ and $6.7 \mathrm{kN} / \mathrm{m}^{2}$, respectively. The building was analyzed as per current Chilean seismic provisions [9] and the ACI318-14 [33] requirements. The building is assumed to be located in seismic zone 3 on soil class $D$, according to the Chilean seismic code NCh433 [9] classification. The seismic force reduction factor $(R)$ prescribed for this system is 4 .

2.2. Modeling Approach. Linear and nonlinear numerical models were considered in this study. Given that the building already exists onsite, the structural element's design was not carried out since dimensions of the elements and the reinforcement layout for each of the elements were available.
Instead, a design check was performed, confirming that their behavior was flexural dominated. The structural drawings were therefore used for modeling the building. The 3D linear elastic model used for this study was first generated using the software package ETABS [34] to determine the structure's main dynamic properties using the response spectrum analysis as per current Chilean seismic regulations [9]. As a result, the cracked fundamental periods of vibrations obtained for the structure were 0.095 and 0.088 seconds in the $x$ - and $y$-directions, respectively, for the second and third main vibration modes (the modes that accumulate $90 \%$ of the mass participation).

Despite the software's capabilities for the linear static analysis, it is not possible to conduct robust nonlinear dynamic analyses. This aspect is relevant for this study as its purpose is to evaluate the effects of ground duration on the seismic behavior of the structure. Therefore, numerical models that accurately characterize structural performance at 
large nonlinear demands should be duly used. To this end, structural models that can capture the in-cycle and cyclic degradation of strength and stiffness of elements are needed [35], since it is the main factor affected by the duration of earthquake records. Therefore, the SeismoStruct software [32] was used to develop a continuous $3 \mathrm{D}$ nonlinear numerical model of the building. This software allows to perform, among several other options, nonlinear dynamic analysis by using accelerograms so that the corresponding loads are applied to the structure. A rigid diaphragm is assumed for each floor. Soil-structure interaction was not considered in this study. The 3D view, floor plan, and elevation of the numerical model of the structure are illustrated in Figure 2.

2.3. Material and Element Models. As previously mentioned, the nonlinear finite element model for the building was developed in SeismoStruct [32]. To this end, the reinforcement details specified in the structural drawings were included in the model. The shear walls were modeled using fiber elements with force-based (FB) formulation [36-38] and using a distributed inelasticity approach along the element length. Gauss-Lobatto numerical integration quadrature rule is used for the FB elements. The fiber-based element model used for the shear walls is presented in Figure 3. A linear elastic hinge at midheight of the walls at each story was provided to capture the elastic shear deformations. It is worth mentioning that the shear hinges' stiffness was equal to the cracked shear area of the walls multiplied by the shear modulus and divided by the story height. A factor of 0.1 was applied to the wall gross area to account for the loss of the area due to cracking [39].

The concrete material was defined using the uniaxial constant confinement model that follows the constitutive relationship proposed by Mander et al. [40] and the cyclic response theory proposed by Martinez-Rueda and Elnashai [41]. The confinement effects provided by the lateral transverse reinforcement were modeled with a confinement factor, defined as the ratio between the confined and unconfined compressive strengths of concrete. In SeismoStruct [32], the confinement factor is calculated using the confinement model proposed by Mander et al. [40]. Table 1 presents the five modelcalibrating parameters defined to fully describe the mechanical features of the concrete. Regarding the reinforcing steel, it was modeled using a uniaxial steel model based on the stress-strain relationship proposed by Menegotto and Pinto [42], coupled with the isotropic hardening rules developed by Filippou et al. [43]. Nine model-calibrating parameters fully describe the mechanical characteristics of the reinforcing steel, which are presented in Table 2. These material models were generated using data calibrated in the laboratory and captured the effect of cycles on sections of reinforced concrete with transverse reinforcement and reinforcement steel elements. The reason these models were used is related to the fact that they are widely accepted by the research community in structural engineering and that they are also well adapted to the events recorded over the past several years in terms of structural performance. The hysteresis rules used for each material model are shown in Figure 4.

\section{Ground Motion Sets}

Two paired sets of spectrally equivalent long- and shortduration records were selected to investigate the effect of ground motion duration on the sample building model. Large-magnitude earthquakes occurred in subduction zones were chosen for the long-duration set and obtained from the 1985 Valparaiso and 2010 Maule, Chile [44], and the 2003 Hokkaido and 2011 Tohoku, Japan [45], earthquakes. Similarly, ground motions from shallow crustal events were chosen from the PEER NGA-West [46] database. Although there is still no consensus in the earthquake engineering community on a standard ground motion duration definition, in this study, the $5 \%$ to $95 \%$ significant duration $\left(D_{s_{5-95 \%}}\right)$ metric was used. This duration metric is defined as the time required to develop the Arias intensity [47] in the range between 5 and $95 \%$ of the total energy of the record [48], as presented in equation (1). Here, $a(t)$ corresponds to the ground motion acceleration record, $T$ is the total duration of the recording, $t_{R}$ is the desired time over which percentage of the total energy is reached (e.g., 90\%), $t$ is the time integration parameter, and $R$ is the calculated fraction of the Arias intensity index:

$$
I_{A}(R \%)=100 \int_{0}^{t_{R}}(a(t))^{2} \mathrm{~d} t \int_{0}^{T}(a(t))^{2} \mathrm{~d} t .
$$

The criterion used to categorize a ground motion as a long or short duration was based on the threshold proposed by Chandramohan et al. [22] upon which a significant duration, $D_{s_{5-95 \%}}$, is higher than $25 \mathrm{~s}$ for long duration and lower than $25 \mathrm{~s}$ for a short duration. The selected longduration ground motions are summarized in Table 3. For brevity, only the component with higher PGA is listed in the table.

To isolate the effect of duration from other ground motion characteristics such as intensity and spectral shape, the methodology proposed by Al Atik and Abrahamson [49] was used to match each ground motion set spectrally. This methodology allows us to obtain spectral equivalence between the long- and short-duration records without having to correct their baseline, which is advantageous since this method ensures the stability and convergence in the calculations. Table 4 summarizes the selected short-duration events and records. These short-duration records were obtained exclusively from worldwide shallow crustal earthquakes. Figures 5(a) and 5(b) depict the geometric mean and standard deviation spectra for the long- and shortduration records. Moreover, Figure 5(c) compares both geometric mean spectrums, indicating a good agreement between both ground motion sets.

\section{Nonlinear Time-History Analysis}

A dynamic time-history analysis was performed in this study. Accordingly, the two sets of ground motions were first scaled to match the NCh 433 design response spectrum for seismic zone 3 and soil class $D$ [9] and then uniformly applied at the base of the building model. The resulting 


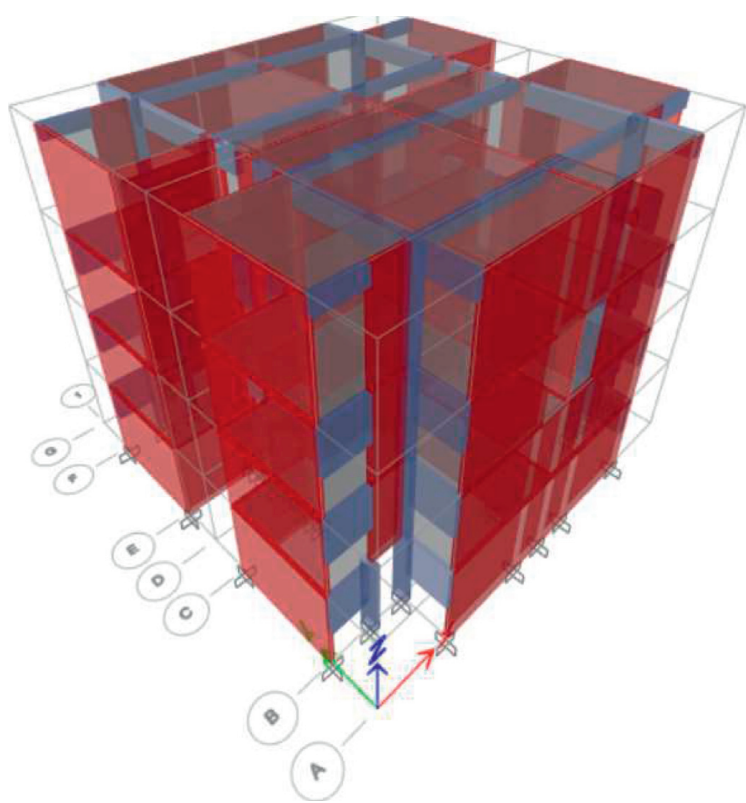

(a)

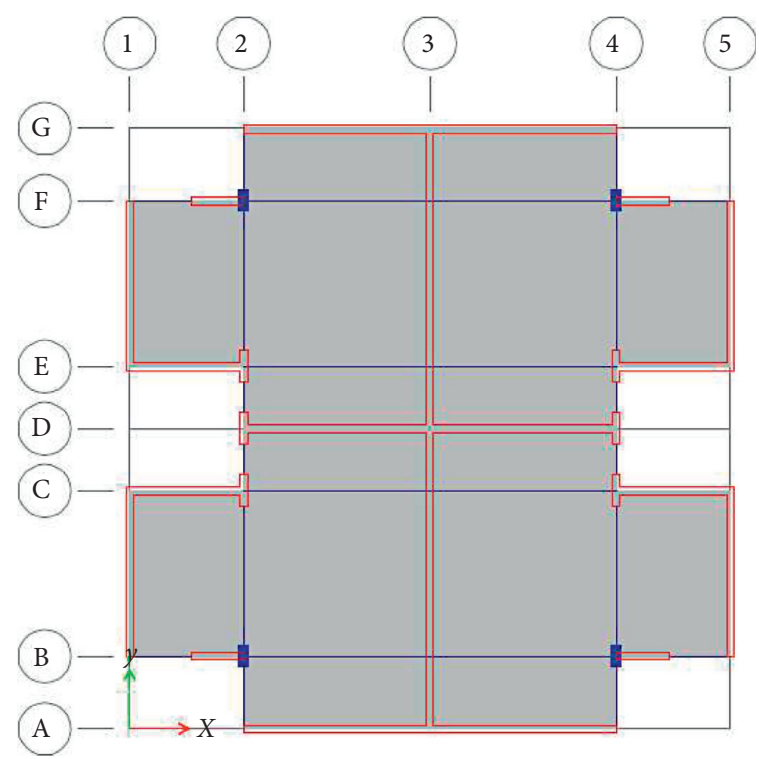

(b)

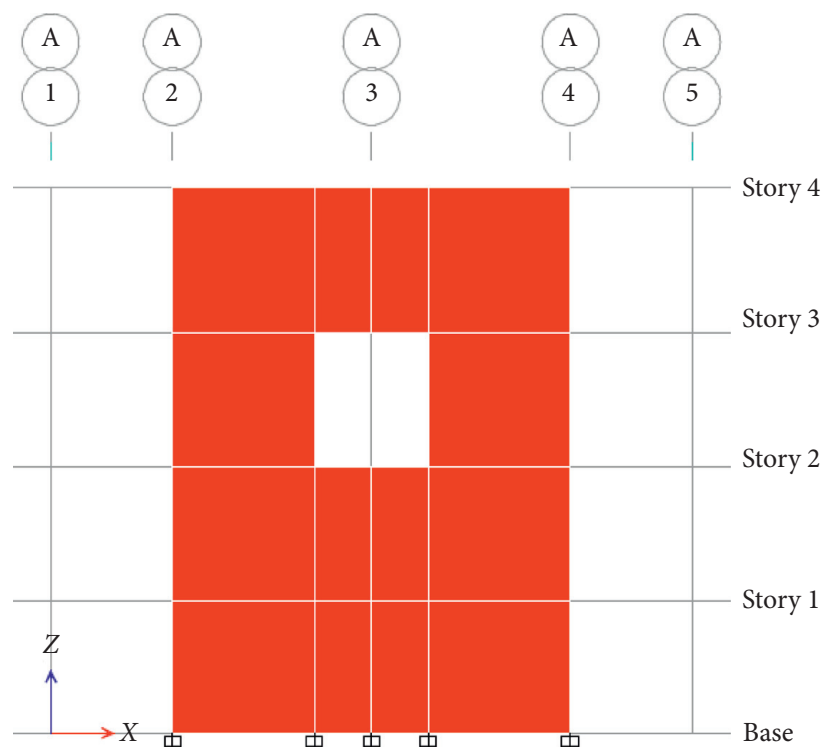

(c)

Figure 2: Low-rise RC building model for numerical analysis: (a) 3D view, (b) typical floor layout, and (c) elevation A1-5.

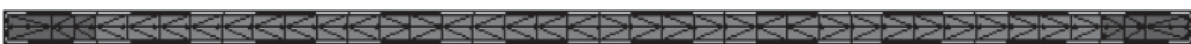

FIgURE 3: Discretized FB element model for RC shear walls.

maximum interstory drifts for the sample building are shown in Figure 6 and were obtained by gathering the available information on the nodes of the structure associated with the center of gravity of the four floors. The NCh433 [9] uses interstory drifts as a damage control parameter and limits the building to a maximum interstory drift of 0.002 of the story height for linear elastic analysis. For the immediate occupancy (IO) evaluation used in the performance-based procedure indicated in the ASCE/SEI 41-17 [11], the maximum interstory drift is limited to 0.004 . As seen in Figure 6, none of the sets surpasses these limits, which might be attributed to the great lateral stiffness of the sample building due to the significant presence of shear walls. When comparing the values obtained for both ground motion sets, there is a slight increase in the interstory drifts for the short-duration ground motion set compared to those for long-duration earthquakes. However, it should be mentioned that the values obtained in both cases are not significantly far from each other, with an increase of $20.05 \%$ for short-duration events. It is, therefore, not possible to 
TABLe 1: Data required to generate the concrete stress-strain curve.

\begin{tabular}{lcc}
\hline & Value & Description \\
\hline$f_{c}$ & $25 \mathrm{MPa}$ & Mean compressive strength \\
$E_{c}$ & $23,500 \mathrm{MPa}$ & Modulus of elasticity \\
$f_{t}$ & $2.5 \mathrm{MPa}$ & Maximum tension strength \\
$\varepsilon_{c}$ & -0.0022 & Strain at peak strength in compression \\
$\varepsilon_{t}$ & -0.0020 & Strain at peak strength in tension \\
\hline
\end{tabular}

TABLE 2: Data required to generate the stress-strain curve of reinforcing steel.

\begin{tabular}{lcc}
\hline & Value & Description \\
\hline$E_{s}$ & $25 \mathrm{MPa}$ & Modulus of elasticity \\
$f_{y}$ & $2 \times 10^{5} \mathrm{MPa}$ & Yield strength \\
$\mu$ & 0.005 & Strain hardening parameter \\
$R_{0}$ & 20 & Transition curve initial shape parameter \\
$A_{1}$ & 18.50 & Transition curve shape calibrating coefficient \\
$A_{2}$ & 0.15 & Transition curve shape calibrating coefficient \\
$A_{3}$ & 0.00 & Isotropic hardening calibrating coefficient \\
$A_{4}$ & 1.00 & Isotropic hardening calibrating coefficient \\
$b$ & 0.1 & Fracture/buckling strain \\
\hline
\end{tabular}

conclude that the short-duration events generate a significant increase in drifts compared to the long-duration events; thus, an incremental dynamic analysis (IDA) was then performed to have a deeper understanding of this phenomenon.

As stated previously, to better estimate the influence of ground motion duration, a series of IDAs were performed to the sample structure, obtaining results for each structural element. IDA is a parametric dynamic analysis technique used in earthquake engineering to conduct a comprehensive assessment of the seismic performance of structures under seismic loads [50]. The procedure involves multiple nonlinear dynamic analysis of a structural model under scaled ground motions until collapse, thus producing curves of engineering demand parameter (EDP) as a damage measure (DM) versus an intensity measure (IM). The ground motions are characterized by the IMs, which should be related to the structural response of interest to reduce the number of time-history analyses [51]. Among the existing IMs, the peak ground acceleration (PGA), peak ground velocity (PGV), spectral acceleration, and Arias intensity are the most widely used. The DM can be any structural parameter related to performance limit states of the structure corresponding to several damage levels. Typical options are the global and local maximum interstory drift, global and local maximum ductility, and material strain limit, among others. In this study, the spectral acceleration at the fundamental period of vibration of the structure with $5 \%$ damping $S_{\text {a }}$ $\left(T_{0}, 5 \%\right)$ while different EDPs was analyzed. Finally, the selected EDPs were the concrete and steel rebar strains for the IDA. It is worth to mention that the collapse stage was defined as the instant at which the main structural walls of the structure failed.

Given that the results for the maximum interstory drift obtained from the nonlinear time-history analysis at the design level of shaking as per Chilean seismic regulations [9] were rather low and not conclusive, the results of the IDA are presented in Figures 7 and 8 for the outer wall of the structure, identified as "A 1-4" according to the floor plan shown in Figure 2. Figure 7 shows slightly higher steel rebar peak strains for the short-duration ground motions compared to the long-duration set. In particular, there is an increase of $8 \%$ in the peak strain of the steel rebar for shortduration events. However, when observing the yield point for the reinforcement steel, 8 cases exceed this point for long-duration events, while 7 cases exceed this point for short-duration events.

Similarly, when considering concrete strains as EDP, the results showed a slight tendency to obtain higher deformations under the short-duration ground motion set. For example, Figure 8 shows 2 cases in which the cracking of concrete occurs at a deformation value exceeding the determined value of 2 per thousand. Meanwhile, for the longduration events, there is only one case for which this limit is exceeded, as can be seen in Figure 8. The obtained peaks of concrete strain show an increase of $17 \%$ for the short-duration suite compared to the long-duration suite for a PGA of $3.8(g)$.

Overall, it is generally possible to observe a slight increase in the demand on the structure under the shortduration ground motion set. In this regard, for this case study and to a slightly greater extent, the demand on the structure in terms of the chosen EDPs was higher under the short-duration earthquakes records than the longduration earthquakes records although minimal damage is expected under both sets of records. This phenomenon should be highlighted since the previous results [22-24, 30] have shown that there are higher levels of deformations, therefore more damage induced by longduration seismic records. However, the unalike results obtained in this research are mainly attributed to the low level of deformation exhibited by the sample structure, which can be supported by the obtained interstory drift values. It should be noted that the structure under consideration was a rather rigid building, with a large 


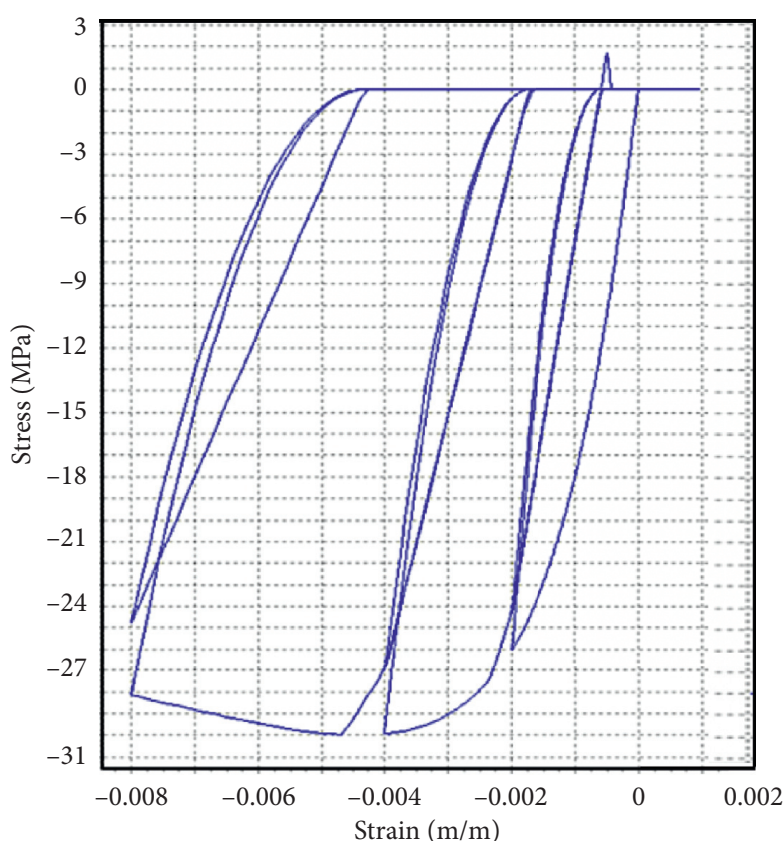

(a)

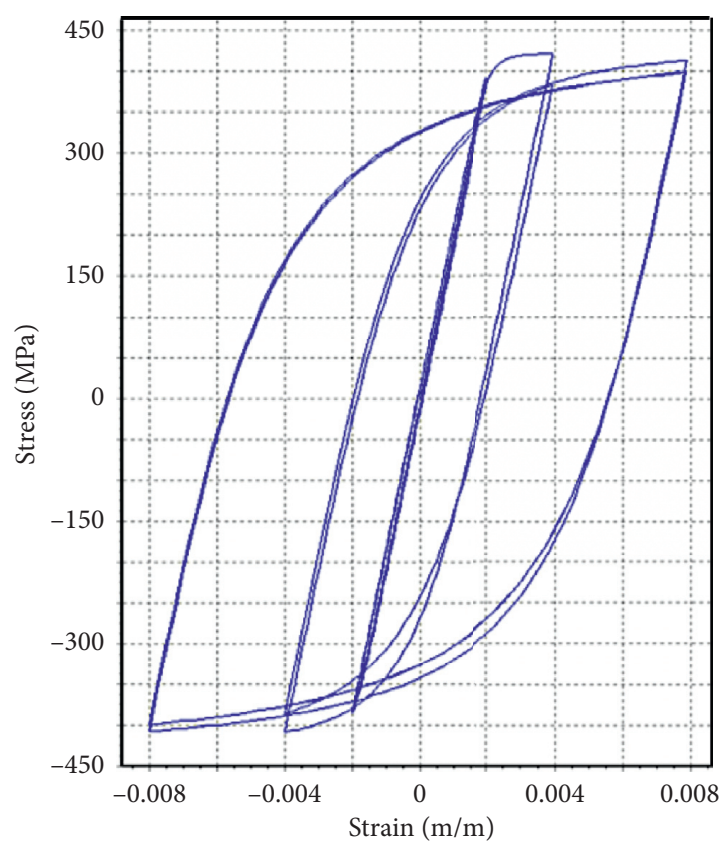

(b)

FIgURE 4: Constitutive models used in the nonlinear numerical model: (a) concrete and (b) reinforcing steel.

TABLE 3: Long-duration set summary.

\begin{tabular}{|c|c|c|c|c|c|}
\hline Earthquake & Magnitude & Year & Station & PGA (g) & Significant duration (s) \\
\hline \multirow{3}{*}{ Valparaiso, Chile } & \multirow{3}{*}{7.8} & \multirow{3}{*}{1985} & Cauquenes & 0.11 & 51.10 \\
\hline & & & Endesa & 0.13 & 44.95 \\
\hline & & & La Ligua & 0.18 & 28.35 \\
\hline \multirow{2}{*}{ Hokkaido, Japan } & \multirow{2}{*}{8.3} & \multirow{2}{*}{2003} & Shibetsu & 0.50 & 32.00 \\
\hline & & & Honbetsukai & 0.48 & 26.96 \\
\hline \multirow{3}{*}{ Maule, Chile } & \multirow{3}{*}{8.8} & \multirow{3}{*}{2010} & Viña Centro & 0.33 & 25.65 \\
\hline & & & Valparaíso & 0.30 & 27.15 \\
\hline & & & Matanzas & 0.34 & 42.15 \\
\hline \multirow{2}{*}{ Tohoku, Japan } & \multirow{2}{*}{9.0} & \multirow{2}{*}{2011} & Tohwa & 0.81 & 58.20 \\
\hline & & & Okhuma & 0.70 & 28.10 \\
\hline
\end{tabular}

TABLE 4: Short-duration set summary.

\begin{tabular}{|c|c|c|c|c|c|}
\hline Earthquake & Magnitude & Year & Station & PGA (g) & Significant duration $(\mathrm{s})$ \\
\hline Cape Mendocino, USA & 7.0 & 1985 & Rio Dell Pass & 0.55 & 15.34 \\
\hline Friuli, Italy & 6.5 & 1976 & Tolmezzo & 0.35 & 16.96 \\
\hline Hector Mine & 7.1 & 1999 & Hector & 0.34 & 11.65 \\
\hline Imperial Valley, & 6.5 & 1979 & El Centro Array\#1 & 0.38 & 17.05 \\
\hline Loma Prieta & 6.9 & 1989 & Gilroy Array\#3 & 0.56 & 6.37 \\
\hline Northridge & 6.7 & 1994 & Canyon Country & 0.48 & 5.56 \\
\hline Northridge & 6.7 & 1994 & Beverly Hills & 0.52 & 9.21 \\
\hline San Fernando & 6.6 & 1971 & LA-Hollywood & 0.21 & 10.49 \\
\hline Superstition Hill & 6.5 & 1987 & El Centro Imp. Co. & 0.36 & 16.05 \\
\hline Superstition Hill & 6.5 & 1987 & Poe Road (temp) & 0.45 & 13.81 \\
\hline
\end{tabular}

presence of walls and a low height, which restricted the deformation capacity and energy dissipation capacity before failure considering how the building was structured. The obtained results confirmed that for structural systems with low ductility capacity, the demand would not be influenced by ground motion duration [23].

\section{Conclusions}

This paper examined the influence of earthquake ground motion duration on the seismic performance of a low-rise RC shear wall building typical of Chilean residential construction. A 3D nonlinear finite element model was 


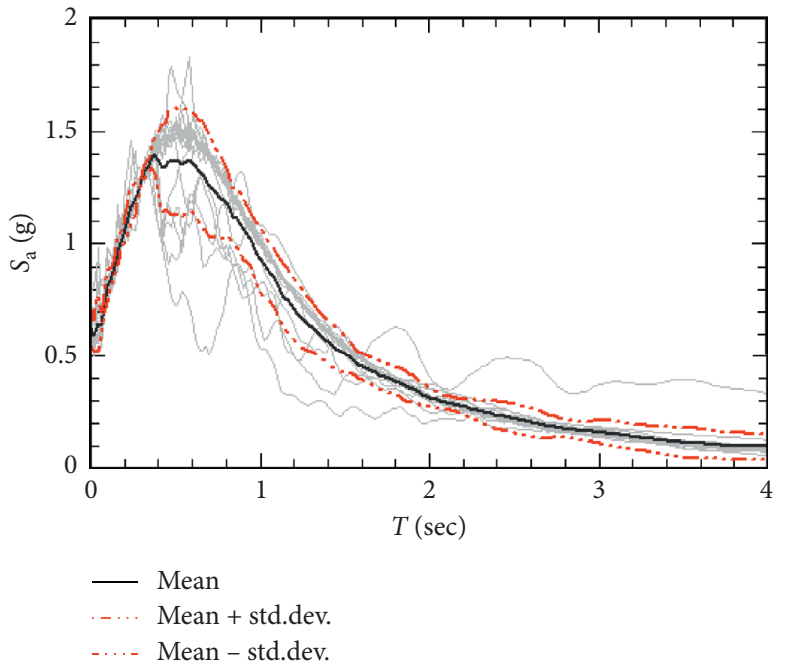

(a)

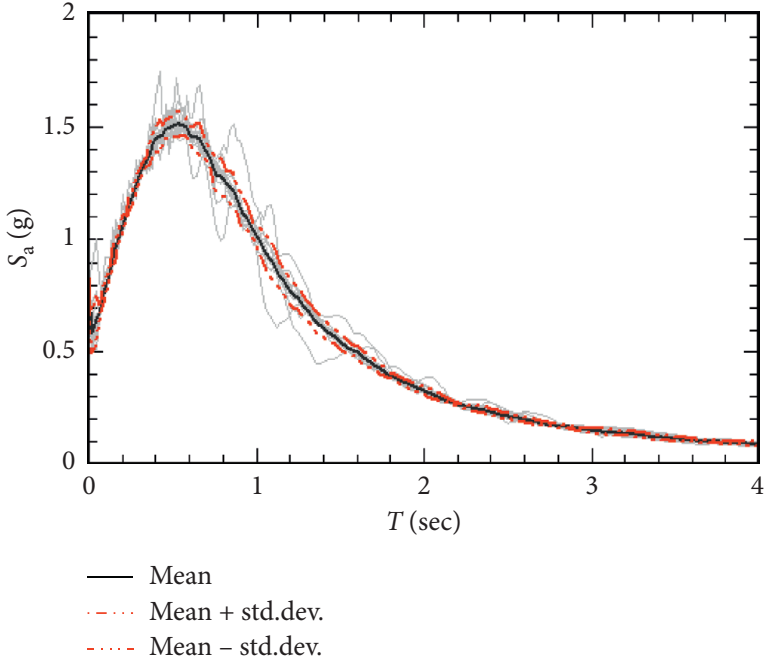

(b)

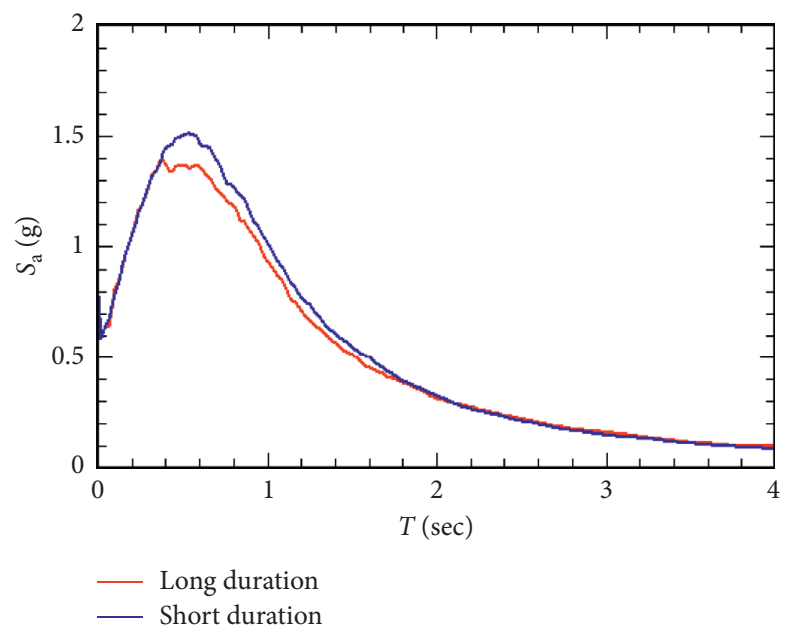

(c)

Figure 5: Geometric mean \pm one standard deviation for spectra of (a) the long-duration set and (b) the spectrally equivalent short-duration set. (c) Comparison between geometric means for both ground motion sets.

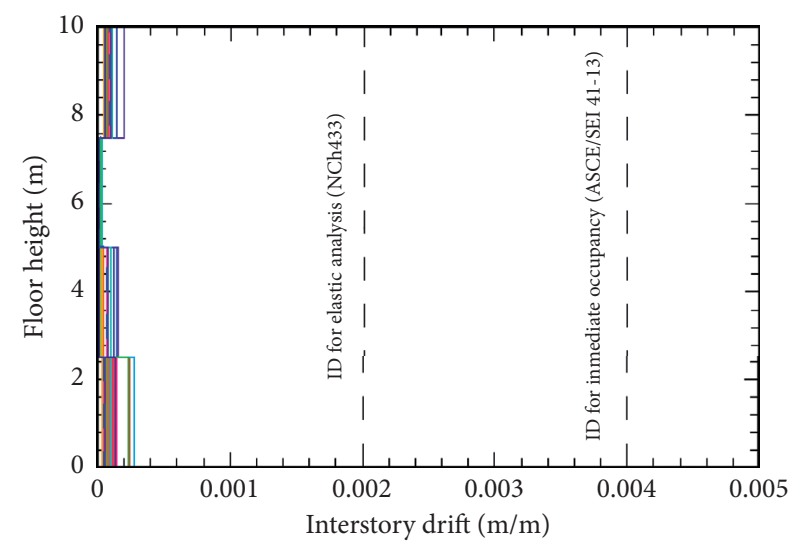

(a)

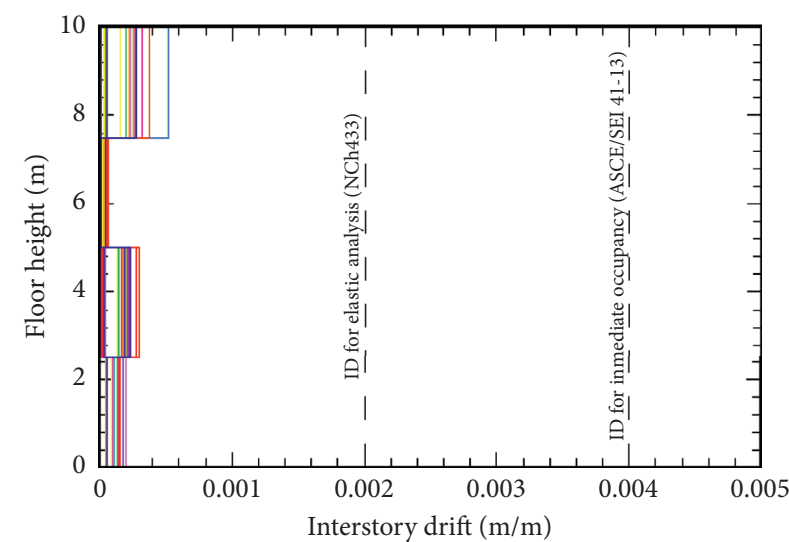

(b)

FIGURE 6: Interstory drift results for the 4-story model as per the Chilean code shaking level for (a) the long-duration set and (b) the shortduration set. 


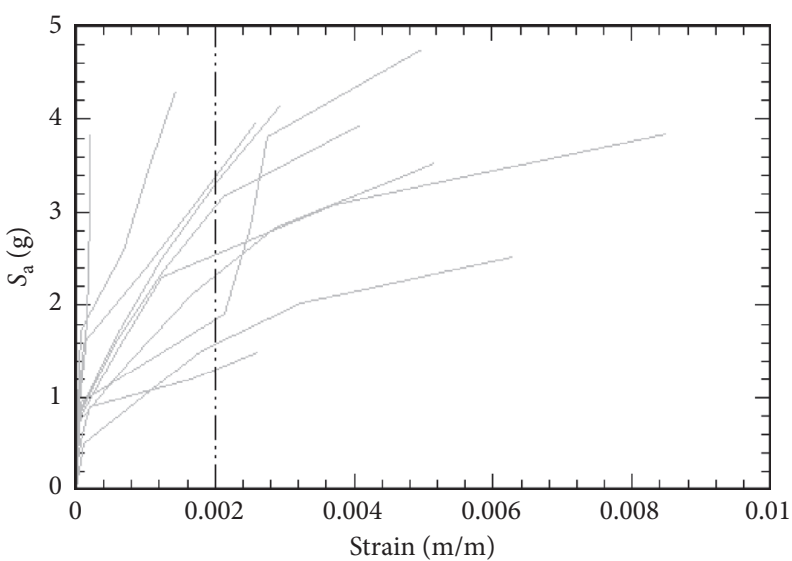

(a)

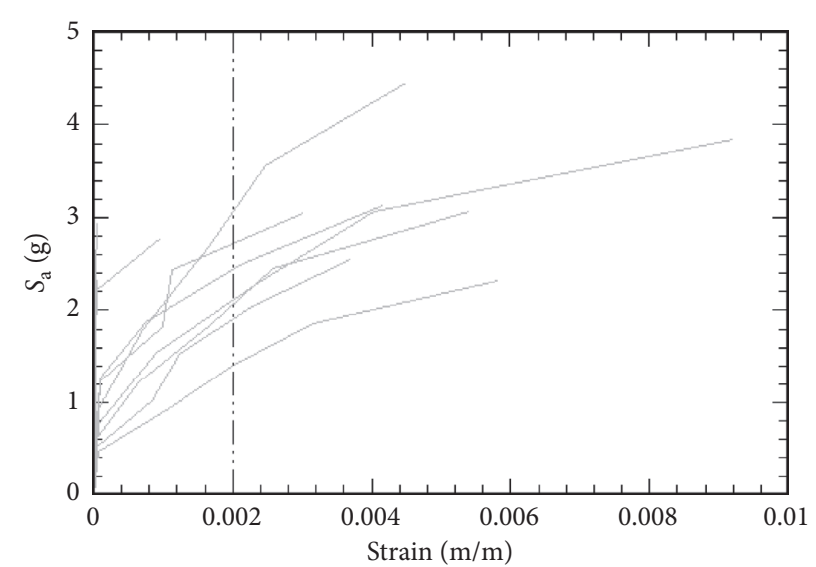

(b)

FIGURE 7: IDA curves considering steel rebar strains as EDP for (a) the long-duration set and (b) the short-duration set.

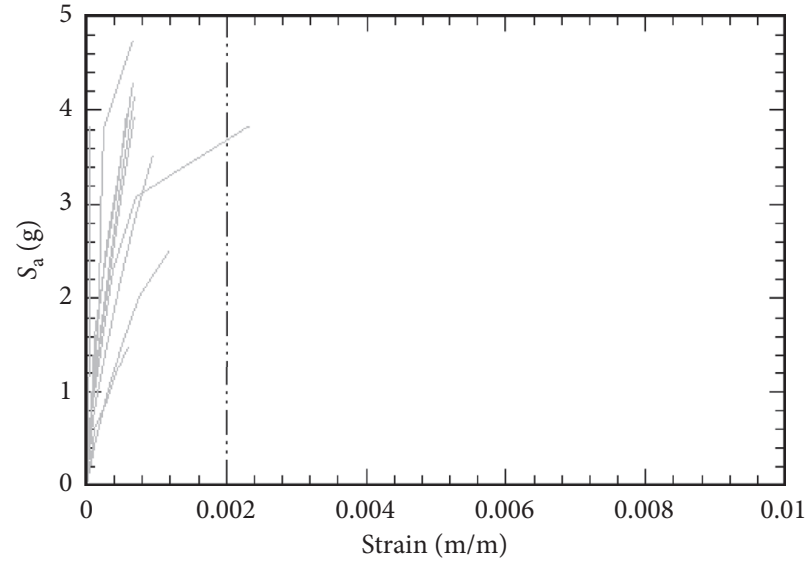

(a)

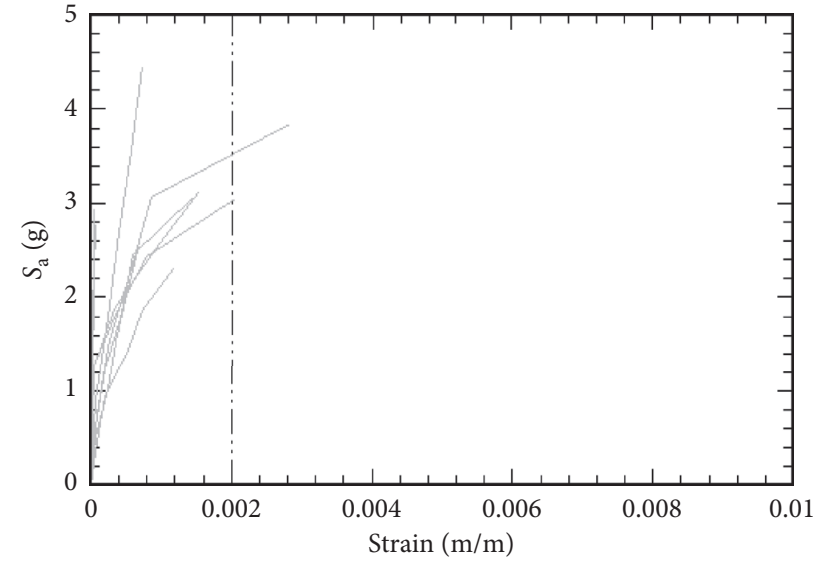

(b)

FIGURE 8: IDA curves considering concrete strains as EDP for (a) the long-duration set and (b) the short-duration set.

developed in SeismoStruct, which explicitly accounted for $P$ delta effects and inherent nonlinearities of the materials. On the other hand, two ground motion sets with equivalent spectral shapes but different durations were obtained to isolate the effects of ground motion duration from other ground motion characteristics. The sample building model was then subjected to time-history analysis at the design level of shaking and to extensive IDA using the long- and shortduration record sets. Overall, the influence of duration was shown to be not significant in the sample structure presented herein.

Based on the results obtained in this study, it is expected that ground motion duration does not influence significantly the peak values of EDPs in low-rise RC shear wall buildings when considering long-duration ground motion records. When comparing the maximum interstory drifts at the design level of shaking to the limits imposed by the NCh433 for linear elastic analysis and the ASCE/SEI 41-17 for performance-based evaluation, the values were found to be small and slight, which resulted in minimum damage to the sample building. Moreover, the structure's behavior regarding the drifts is generally quite similar in both situations and slightly higher for the short-duration set than for the long-duration set. It should be mentioned that the structure was designed as per the current seismic Chilean seismic code, which resulted in a rather rigid structure. The behavior of the structure in terms of deformations was consequently restricted to its linear range, which led to low levels of deformation capacity.

To better understand the effect of the duration of earthquakes on the structure thoroughly, the sample building was subjected to incrementally scaled ground motion records to higher levels of shaking using IDA. Concrete and steel rebar strains were used as EDPs. The results showed a slight difference between the curves obtained for short-duration records and those obtained for long-duration records. Regarding the material peak strains, higher peaks by approximately $8 \%$ for reinforced steel and by approximately $17 \%$ for concrete were obtained for shortduration events. Furthermore, it should be noted that an increase in material strains for the short-duration events was generally obtained although this increase was not significant. The results obtained in this study confirmed that for structural systems with low ductility capacity, the influence 
of duration is not significant due to the incapacity to reach large deformation and dissipate energy before failure.

Further research is recommended to study structures that can reach higher levels of deformation to obtain a relevant structural demand regarding seismic loading and results related to the performance of the materials considering their nonlinear behavior. Thereby, it would be possible to have a deeper and a more conclusive understanding of the effect of the duration of a seismic event since the increased number of cycles imposed by long-duration ground motions are one of the main concerns when conducting such studies.

\section{Data Availability}

Some or all data, models, or code generated or used during the study are available from the corresponding author upon request.

\section{Conflicts of Interest}

The authors declare that there are no conflicts of interest regarding the publication of this paper.

\section{Acknowledgments}

The authors wish to acknowledge the support from the School of Civil Engineering of the Pontificia Universidad Católica de Valparaíso for providing the funds for the publication of this article. This research has been possible thanks to the support of the School of Civil Engineering from the Pontificia Universidad Católica de Valparaíso.

\section{References}

[1] C. Alarcon, M. A. Hube, R. Jünemann, and J. C. de la Llera, "Characteristics and displacement capacity of reinforced concrete walls in damaged buildings during 2010 Chile earthquake," Bulletin of Earthquake Engineering, vol. 13, no. 4, pp. 1119-1139, 2015.

[2] K. Kawashima and I. Buckle, "Structural performance of bridges in the Tohoku-oki earthquake," Earthquake Spectra, vol. 29, no. 1, 2013.

[3] I. Buckle, M. Hube, G. Chen, W. H. Yen, and J. Arias, "Structural performance of bridges in the offshore maule earthquake of 27 February 2010," Earthquake Spectra, vol. 28, no. 1, pp. 533-552, 2012.

[4] F. Rojas, F. Naeim, M. Lew et al., "Performance of tall buildings in concepción during the 27 February 2010 moment magnitude 8.8 offshore Maule, Chile earthquake," The Structural Design of Tall and Special Buildings, vol. 20, no. 1, pp. 37-64, 2011.

[5] R. Saragoni and G. Hart, "Simulation of artificial earthquakes," Earthquake Engineering \& Structural Dynamics, vol. 2, no. 3, pp. 249-267, 1973.

[6] R. Tremblay, "Development of design spectra for long-duration ground motions from Cascadia subduction earthquakes," Canadian Journal of Civil Engineering, vol. 25, no. 6, pp. 1078-1090, 1998.

[7] M. Sarieddine and L. Lin, "Investigation correlations between strong-motion duration and structural damage," in Proceedings of the 2013 Structures Congress, pp. 2926-2936, Pittsburgh, PA, USA, May 2013.
[8] ASCE, Minimum Design Loads for Buildings and Other Structures, ASCE/SEI 7-16 Press, Reston, VA, USA, 2016.

[9] Instituto Nacional de Normalizacion, Diseno Sismico de Edificios, Instituto Nacional de Normalizacion, Santiago, Chile, in Spanish, 2012.

[10] CEN, Eurocode 8: Design of Structures for Earthquake Resistance-Part 1: General Rules, Seismic Actions and Rules for Buildings, No. English, The European Union Per Regulation 305/2011, Directive 98/34/EC, Directive 2004/18/EC, 2004.

[11] ASCE, Seismic Evaluation and Retrofit of Existing Structures ASCE/SEI 41-17, ASCE/SEI 7-16 Press, Reston, VA, USA, 2014.

[12] FEMA P695, Quantification of Building Seismic Performance Factors, FEMA, Washington, DC, USA, 2009.

[13] C. Oyarzo-Vera and C. Nawawi, "Effect of earthquake duration and sequences of ground motions on structural responses," in Proceedings of the 10th International Symposium on Structural Engineering for Young Experts ISSEYE, pp. 1881-1886, Changsha, China, January 2008.

[14] J. Hancock and J. J. Bommer, "A state-of-knowledge review of the influence of strong-motion duration on structural damage," Earthquake Spectra, vol. 22, no. 3, pp. 827-845, 2006.

[15] I. Iervolino, G. Manfredi, and E. Cosenza, "Ground motion duration effects on nonlinear seismic response," Earthquake Engineering \& Structural Dynamics, vol. 35, no. 1, pp. 21-38, 2006.

[16] A. Dutta and J. B. Mander, "Energy based methodology for ductile design of concrete columns," Journal of Structural Engineering, vol. 127, no. 12, pp. 1374-1381, 2001.

[17] E. Bojorquez, I. Iervolino, G. Manfredi, and E. Cosenza, "Influence of ground motion duration on degrading SDOF systems," in Proceedings of the 16 th European Conference on Earthquake Engineering and Seismology, pp. 3-8, Geneva, Switzerland, September 2006.

[18] C. A. Cornell, "Does duration really matter?" in Proceedings of the FHWA/NCEER Workshop on the National Representation of Seismic Ground Motion for New and Existing Highway Facilities, pp. 125-133, Burlingame, CA, USA, May 1997.

[19] V. Bhanu, R. Chandramohan, and T. J. Sullivan, "Investigating the influence of ground motion duration on the dynamic deformation capacity of reinforced concrete framed structures," in Proceedings of the 11th Pacific Conference on Earthquake Engineering, Auckland New Zealand., April 2019.

[20] J. Hancock and J. J. Bommer, "Using spectral matched records to explore the influence of strong-motion duration on inelastic structural response," Soil Dynamics and Earthquake Engineering, vol. 27, no. 4, pp. 291-299, 2007.

[21] M. Mashayekhi, M. Harati, M. Ashoori Barmchi, and H. E. Estekanchi, "Introducing a response-based duration metric and its correlation with structural damages," Bulletin of Earthquake Engineering, vol. 17, no. 11, pp. 5987-6008, 2019.

[22] R. Chandramohan, J. W. Baker, and G. G. Deierlein, "Quantifying the influence of ground motion duration on structural collapse capacity using spectrally equivalent records," Earthquake Spectra, vol. 32, no. 2, pp. 927-950, 2016.

[23] M. Raghunandan and A. B. Liel, "Effect of ground motion duration on earthquake-induced structural collapse," Structural Safety, vol. 41, pp. 119-133, 2013.

[24] A. R. Barbosa, F. L. A. Ribeiro, and L. A. C. Neves, "Influence of earthquake ground-motion duration on damage estimation: application to steel moment resisting frames," 
Earthquake Engineering \& Structural Dynamics, vol. 46, no. 1, pp. 27-49, 2017.

[25] M. A. Bravo-Haro and A. Y. Elghazouli, "Influence of earthquake duration on the response of steel moment frames," Soil Dynamics and Earthquake Engineering, vol. 115, pp. 634-651, 2018.

[26] A. Belejo, A. R. Barbosa, and R. Bento, "Influence of ground motion duration on damage index-based fragility assessment of a plan-asymmetric non-ductile reinforced concrete building," Engineering Structures, vol. 151, pp. 682-703, 2017.

[27] A. Samanta and P. Pandey, "Effects of ground motion modification methods and ground motion duration on seismic performance of a 15-storied building," Journal of Building Engineering, vol. 15, pp. 14-25, 2018.

[28] E. Vega and L. A. Montejo, "Influence of ground motion duration on ductility demands of reinforced concrete structures," International Journal of Advanced Structural Engineering, vol. 11, no. 4, pp. 503-517, 2019.

[29] M. Liapopoulou, M. A. Bravo-Haro, and A. Y. Elghazouli, "The role of ground motion duration and pulse effects in the collapse of ductile systems," Earthquake Engineering \& Structural Dynamics, vol. 49, no. 11, pp. 1051-1071, 2020.

[30] A. Mantawy and J. C. Anderson, "Effect of long-duration earthquakes on the low-cycle fatigue damage in RC frame buildings," Soil Dynamics and Earthquake Engineering, vol. 109, pp. 46-57, 2018.

[31] R. Dobry, I. M. Idriss, and E. Ng, "Duration characteristics of horizontal components of strong-motion earthquake records," Bulletin of the Seismological Society of America, vol. 68, no. 5, pp. 1487-1520, 1978.

[32] SeismoSoft, 2019, SeismoStruct 2019-A Computer Program for Static and Dynamic Nonlinear Analysis of Framed Structures, https://www.seismosoft.com/.

[33] ACI Committee 318, Building Code Requirements for Structural Concrete, ACI Committee 318, Farmington Hills, MI, USA, 2014.

[34] CSI, CSI ETABS Analysis Reference Manual, Comput. Struct. Inc., Berkeley, CA, USA, 2013.

[35] L. F. Ibarra, R. A. Medina, and H. Krawinkler, "Hysteretic models that incorporate strength and stiffness deterioration," Earthquake Engineering \& Structural Dynamics, vol. 34, no. 12, pp. 1489-1511, 2005.

[36] E. Spacone, F. C. Filippou, and F. F. Taucer, "Fibre beamcolumn model for non-linear analysis of R/C frames: part I. Formulation," Earthquake Engineering \& Structural Dynamics, vol. 25, no. 7, pp. 727-742, 1996.

[37] E. Spacone, F. C. Filippou, and F. F. Taucer, "Fibre beamcolumn model for non-linear analysis of R/C frames: part II. Applications," Earthquake Engineering \& Structural Dynamics, vol. 25, no. 7, 1996.

[38] A. Neuenhofer and F. C. Filippou, "Evaluation of nonlinear frame finite-element models," Journal of Structural Engineering, vol. 123, no. 7, pp. 958-966, 1997.

[39] J. S. Pugh, L. N. Lowes, and D. E. Lehman, "Seismic design of slender concrete walls," in Proceedings of the 10th U.S. National Conference on Earthquake Engineering Frontiers of Earthquake Engineering, Anchorage, AK, USA, July 2014.

[40] J. B. Mander, M. J. N. Priestley, and R. Park, "Theoretical stress-strain model for confined concrete," Journal of Structural Engineering, vol. 114, no. 8, pp. 1804-1826, 1988.

[41] J. Martínez-Rueda and A. S. Elnashai, "Confined concrete model under cyclic load," Materials and Structures, vol. 30, no. 3, pp. 139-147, 1997.
[42] M. Menegotto and P. E. Pinto, "Method of analysis for cyclically loaded R. C. plane frames including changes in geometry and non-elastic behavior of elements under combined normal force and bending," Proceedings of IABSE Symposium on Resistance and Ultimate Deformability of Structures Acted on by Well Defined Repeated Loads, pp. 15-22, 1973.

[43] F. C. Filippou, E. P. Popov, and V. V. Bertero, "Effects of bond deterioration on hysteretic behaviour of reinforced concrete joints," Report, National Science Foundation, Berkeley, CA, USA, 1983.

[44] University of Chile, Earthquakes of Chile, University of Chile, Santiago, Chile, 2010.

[45] K-NET, Kyoshin Network Database, National Research Institute for Earth Science and Disaster Resilience, 2019.

[46] Pacific Earthquake Engineering Research Center, PEER Ground Motion Database, Shallow Crustal Earthquakes in Active Tectonic Regimes, NGA-West2, 2017.

[47] A. Arias, A Measure of Earthquake Intensity, Seismic Design for Nuclear Power Plants, MIT Press, Cambridge, MA, USA, 1970.

[48] M. D. Trifunac and A. G. Brady, "A study on the duration of strong earthquake ground motion," Bulletin of the Seismological Society of America, vol. 65, no. 3, pp. 581-626, 1975.

[49] L. Al Atik and N. Abrahamson, "An improved method for nonstationary spectral matching," Earthquake Spectra, vol. 26, no. 3, pp. 601-617, 2010.

[50] D. Vamvatsikos and C. Allin Cornell, "Incremental dynamic analysis," Earthquake Engineering \& Structural Dynamics, vol. 31, no. 3, pp. 491-514, 2002.

[51] J. Kiani and S. Pezeshk, "Sensitivity analysis of the seismic demands of RC moment resisting frames to different aspects of ground motions," Earthquake Engineering \& Structural Dynamics, vol. 46, no. 15, pp. 2739-2755, 2017. 